\title{
Brief Acceptance and Commitment Group Therapy for Nursing Home Staff: Effects on Stress, Performance, and Quality of Life
}

\author{
Annisa Rahmalia \\ Faculty of Psychology, Department of Clinical Psychology, \\ Universitas Indonesia \\ annisa.rahmalia72@ui.ac.id \\ Yudiana Ratnasari \\ Faculty of Psychology, Department of Clinical Psychology, \\ Universitas Indonesia \\ judiana.ratna@ui.ac.id
}

\begin{abstract}
Staff working in nursing homes holds important roles for caregiving older adults, yet they are prone to experiencing high stress due to high demands at work. Two core processes in Acceptance and Commitment Therapy (ACT): personal values and committed action offers new strategies for nursing home staff to create a more positive attitude, thus potential in improving nursing home staff's general mental health. This study explores the effects of brief-ACT on psychological flexibility, work stress, in-role performance, and quality of life among nursing home staff. Therapy was conducted in a group setting, emphasizing personal values and committed action core processes, with quantitative measurements administered in pretest-posttest design. Participants also answered open-ended questions for qualitative results regarding with effects of the group therapy. Results showed statistically significant effects of Brief-ACT for psychological flexibility, in-role performance, and quality of life, while the decrease in work stress was not statistically significant. In addition, qualitative themes coded from open-ended questions reported positive experiences related to the group therapy. This study provides initial findings regarding ACT feasibility among nursing home staff, particularly related to personal values and committed action core processes.
\end{abstract}

Keywords: $A C T$, nursing home staff, values, committed action, work stress.

Received 26 April 2021/Accepted 18 August 202I @Author all rights reserved

\section{Introduction}

The number of older adults tends to increase every year, with people aged 65 years or older in developing countries contributes to approximately $20 \%$ of the total population by 2050 (Chen et al., 2017). This trend is also observed in Indonesia, with an estimation to reach $15 \%$ of the total population by 2035 (BPS, 2018). The fast-growing number of older adults projected to increase the demand for 


\section{Journal of Educational, Health and Community Psychology Rahmalia, \\ Vol I0, No 3, 202 I E-ISSN 2460-8467 Ratnasari.}

nursing homes, with nursing homes relying on their frontline staff for caregiving roles (Cagle et al., 2017). However, previous studies suggest that nursing home staff may not be trained adequately for their patients' palliative care (Cagle et al., 2017). Caregiving for older adults requires a particular set of skills with proper training (Grunfeld et al., 2004), limiting the human resources available for the role. Worries exist in nursing home arrangements where more staff is needed (Willemse et al., 20II), leading to the disproportion between caregivers and care recipients' ratio. This situation exposed the current nursing home staff, particularly with caregiver roles, to a higher risk of experiencing job stress due to the immense job demand at work.

Furthermore, nursing home care has been inherently labor-intensive (Castle, Engberg, \& Men, 2007). Various challenges faced by caregivers may have positive impacts, but there are also adverse effects on physical, emotional, social, and financial domains (Olzmann, 2017). Ultimately, the resulting adverse effects can lead to high work stress among caregivers (Banaszak-Holl \& Hines, 1996), particularly among the nursing home staff. High job stress puts caregivers at high risk of facing various psychological problems such as loneliness, depression, anxiety, and lower quality of life (Tumanggor, Elfira, \& Aizar, 2020). In the long term, high job stress from excessive workload beyond the individual capability is one of the risk factors for burnout (Mustafa, 20I5). Other problems related to this issue are nursing home staff turnover (Banaszak-Holl \& Hines, 1996), lower job satisfaction (Parsons, Simmons, Penn, \& Furlough, 2003), and potential adverse health outcomes for nursing home residents (Castle, Engberg, \& Men, 2007). Work stress from daily challenges (challenge stressors) is also one of the factors that contribute to a decrease in in-role performance among staff (Sonnentag, Volmer, Spychalla, 2008) when the stress is appraised as a threat (González-Morales \& Neves, 20I5). Different domains of work stress are also associated with all the domains in quality of life (Babu et al., 20l6).

In Jakarta, Indonesia's capital city, several nursing homes are governed by the Social Services and accommodated by nearly 5,309 older adults (Jakarta Open Data, 2018). Sasana Tresna Werdha (STW) Centex is one of Jakarta's nursing homes and is mainly operated by the Jakarta City Social Service. STW Centex provides care for around 35 older adults with only about seven employees ( $1: 5$ ratio of nursing home staff and care recipients). The ratio disproportion of caregivers and care recipients adds 
further burden for the nursing home staff, as most of the staff are also involved in other functional roles and administrative positions. Based on observation and informal interviews previously conducted with the nursing home staff in STW Centex, their daily job tasks and demands remains very high, with the responsibility to care for most of the older adults and serve their respective positions' functional duties. Double-duty caregivers prove to be employees who are at risk of developing symptoms of overload (Boumans \& Dorant, 2014). Another challenge faced by the nursing home staff is that more than $70 \%$ of the older adults in STW Centex also suffer from various physical and psychological problems, such as dementia, mild affective disorders, anger issues, and degenerative physical conditions such as hypertension, diabetes, decreased sensory function, and infectious diseases. The care recipients' various conditions increase nursing home staff's workload due to no previous caregiver training to provide care for the older adults with current physical and psychological problems. Nursing homes differ from other healthcare settings in that they have a diverse range of medical problems and needs of their residents, resulting in a stressful environment (Cohen-Mansfield, 1995; Moody, 1983).

The interviews and observations conducted in STW Centex also highlight the nursing home staffs work stress, such as feeling demotivated to work and wanting to quit their job. Consistent with previous research, some nursing home staff in the United States report emotional exhaustion and a sense of depersonalization resulting from high stress (Jackson et al., 1986, Maslach, 1982). One of the employees also explained the imbalance in the workload, where some other staff was considered less involved in their work than the other staff on duty. This situation triggers a harmful social environment, where several nursing home staff became involved in harmful social interactions and got into conflict due to the negative attitudes toward each other. For the care recipients, the unhealthy social environment is potentially detrimental to the nursing home staffs quality of care (Goergen, 200I), leading to the disruptions of older adult's welfare in the nursing home, potentially adverse health outcomes for residents (Castle, Engberg, \& Men, 2007), and additional costs of personnel training (Iglehart, 1990). The high work stress also affects the quality of life of nursing home staff, where several employees complained about excessive working hours, minimum time breaks, and stagnancy in their job tasks. Previous research suggests that work stress is associated with lower quality of life, particularly when individuals posit lower control over their job in the workplace (Lu et al., 2019). 


\section{Journal of Educational, Health and Community Psychology Rahmalia, \\ Vol I0, No 3, 202 I E-ISSN 2460-8467 Ratnasari.}

High work stress is one of the risk factors of burnout among nursing home staff, which may cause staff turnover. These negative impacts highlight the need to develop stress management strategies to lower work stress, improve in-role performance and quality of life among nursing home staff. These strategies are also one of the preventive measures of burnout and staff turnover for nursing home staff by creating a more positive attitude towards work and job tasks. Several interventions can be done to deal with work stress, such as stress management educational materials, biofeedback, conflict management workshops, meditation and relaxation techniques, and other cognitive-behavioral approaches (Murphy \& Sauter, 2003). Cognitive-Behavioral Therapy (CBT) is one of the most widely used interventions to deal with job stress. However, literature studies show that CBT only shows modest improvements, and the effect decreases over time (Collins, O’Brien, \& Winterich, 2003), other study shows that the therapy results are still inconsistent (George, 2016). One explanation for this may be that CBT partially requires individuals to actively identify and change their negative thoughts, which is complicated for most individuals (Schwetschenau, 2008; George, 2016).

Acceptance and Commitment Therapy (ACT) is a novel therapeutic method that that differs from cognitive behavioral therapy (CBT), which does not force individuals to change their negative thoughts but instead aims for individuals to accept their negative experiences (Schwetschenau, 2008). This approach results in a more controlled emotional reaction toward negative experiences, thus offering a new approach to deal with work stress. Acceptance of experience is one way to form a positive attitude towards work. The primary purpose of ACT is to increase psychological flexibility, namely, to recognize and adapt to various life changes (Hayes \& Strosahl, 2004). Several research results show that ACT therapy results are rather beneficial for caregivers, such as reducing levels of depression, anxiety, and adverse effects in family members who are caregivers for dementia patients (Losada et al., 20I5; Marquez-Gonzalez et al., 20I4). The study results also showed that telephone-based ACT helped significantly reduce caregiver difficulties in dealing with lung cancer in care recipients (Mosher et al., 2019).

There are six core processes of psychological flexibility in ACT_acceptance, cognitive defusion, selfas-context, flexible attention to the present moment, values, and committed action- each plays a 
fundamental role in human adaptability to both changing and challenging circumstances of life (Hayes, Strosahl, \& Wilson, 2012). While all processes are related to each other, there are also more deeply interlinked processes defined into three response styles: open, centered, and engaged ACT processes (Hayes, Strosahl, \& Wilson, 20I2). Seeing the conditions at STW Centex, the engaged stage is an essential step for nursing home staff to be psychologically and physically healthier in facing the demands of their daily work, as the engaged stage guides individuals to lead a meaningful life, produce a sense of vitality, life connectedness, and sense of health and well-being (Hayes, Strosahl, \& Wilson, 20I2). Engaged living is the concept defined as the evaluation and performance of valued life activities (Trindade et al., 2015), which results from personal values and committed action core processes in ACT. According to Hayes' theoretical model, engaged living has been linked to increased life fulfillment, improved psychological quality of life, and reduced psychological distress (Trompetter et al., 2013; Wilson \& Murrell, 2004). Previous study showed that individual values were related to commitment in the workplace (Cohen \& Liu, 20II), and committed action also accounted for variance beyond values in the prediction of overall stress, depression levels, systolic blood pressure, and heart rate (Crudup, 2016).

Engaged living also showed a significant negative relationship with psychological inflexibility, and significantly predicted positive well-being (Schmelzer, 2017). Engaged living, according to the literature, is likely to improve one's physical and psychological health and well-being (Trindade et al., 20I5), and empirical findings show that identifying and clarifying personal values appears to keep neuroendocrine and psychological responses at low levels (Cresswell et al., 2005). Subsequently, engaged living through ACT leads to effective working and motivates to pursue an actual valued and complete life (Trindade et al., 2015). Overall, these data suggest that clinical work on valuing and engaged living may help mitigate the psychological and physiological effects of stressful external and internal situations. However, access to a proper psychological therapy remains limited in frontline services such as nursing home staff, and the high cost of training and supervising therapists in sufficient numbers to meet demand has led to evaluations of briefer, group-based interventions to improve the potential for costeffective delivery (Walser \& Pistorello, 2004). Group therapy offers a more efficient method and may 
confer additional benefits, such as social support from peers, normalizing process, and access to other perspectives in the same group (Ruddle, Mason, \& Wykes, 20I I; Walser \& Pistorello, 2004).

The empirical findings have been valuable in describing how values and committed action core processes provide potential benefits for staff working in nursing home settings; however, no study has examined the effects of both processes (which results in engaged living) conducted in group intervention setting among nursing home staff. Several studies found positive effects of ACT for family caregivers of adults with dementia (Fowler et al., 202I; Losada et al., 2015). ACT conducted in group setting also provides new findings when conducted among caregivers of chronic illness patients (Williams et al., 2014) and among informal caregivers of people with psychosis (Jolley et al., 2020). O'Brien et al. (2019) examined group-based ACT for nurses working in long-term care settings, with results confirmed that group ACT promote improvements in well-being for nurses working in longterm care settings. There is limited prior research related to ACT being focused on personal values and committed action core processes implemented in workers. A study conducted by Castro, Rehfeldt, \& Root (2016) found that values clarifications and committed action workshops enhance the engagement of direct care staff with clients with severe developmental disorders. To our knowledge, this study is the first to have isolated the effects of both personal values and committed action core processes conducted in group setting, on psychological flexibility, work stress, in-role performance, and quality of life in nursing home staff. Therefore, this study is an intervention study that aims to examine the effectiveness of Brief-ACT group therapy to improve psychological flexibility, reduce work stress, and improve both in-role performance and quality of life among nursing home staff. The group therapy will be conducted with two main ACT processes-values and committed action-to promote a more positive attitude towards work in nursing home staff.

\section{Method}




\section{Journal of Educational, Health and Community Psychology Rahmalia, \\ Vol I0, No 3, 202 I E-ISSN 2460-8467 Ratnasari.}

\section{Participants}

Nursing home staff from STW Centex, Jakarta, Indonesia, was chosen as participants in the study based on an initial qualitative assessment conducted by the author. All nursing home staff from STW Centex $(n=7)$ were assessed using informal interviews and observation, and results found where all the staff reported symptoms related to high work stress in the nursing home. This initial assessment also highlights the need to develop a new stress development strategy as the unhealthy social environment also affects staff performance and quality of life in the nursing home. Sociodemographic data for all staff were collected from institutional staff records and self-administered participant biodata forms. Participation was voluntary, and the study had no exclusion or inclusion criteria. All the nursing home staff agreed to participate and completed written informed consent before participating in the group therapy. After consent was obtained, questionnaires on nursing home staff's work stress, psychological flexibility, in-role performance, and quality of life were distributed to all participants as a pretest before group therapy.

Table I

Participant Sociodemographic Data

\begin{tabular}{lllllll}
\hline Participant & Age & Gender & Marital status & Position & Education & Duration of work* \\
\hline A & 52 & Female & Married & Director & Bachelor's degree & 8 months \\
B & 43 & Male & Married & Administrative & High school degree & 6 months \\
C & 25 & Male & Single & Social worker & Bachelor's degree & 2 years \\
D & 39 & Male & Married & Cleaning service & High school degree & 2 years \\
E & 56 & Male & Married & Security & High school degree & I year \\
F & 49 & Female & Married & Cook & High school degree & 2 years \\
G & 43 & Female & Divorced & Washer & High school degree & I year \\
\hline
\end{tabular}

* Duration of working in the nursing home.

\section{Design}

This quasi-experimental study examined the effects of Brief-ACT group therapy on psychological flexibility, work stress, in-role performance, and quality of life among nursing home staff. Data were collected using quantitative and qualitative methods through questionnaires with psychological instruments and open-ended questions about participants' experience related to the group therapy. For the quantitative data collection, this study was conducted with one group pretest-posttest research design. Meanwhile, qualitative data collection using open-ended questions was conducted four 


\section{Journal of Educational, Health and Community Psychology Rahmalia, \\ Vol I0, No 3, 202 I E-ISSN 2460-8467 Ratnasari.}

times after every session was completed and one time after the whole group therapy was completed. There was only one group of participants who received Brief-ACT group therapy.

\section{Procedure}

From the initial interviews and observations, it has been found that there are several reports of symptoms related to high work stress; therefore, the pretest was conducted to figure the baseline condition among the participants. The group therapy consists of four sessions: two sessions for choosing values core process and two sessions for a committed action core process. Each session was held for 90-120 minutes twice a week, thus within two weeks duration. The purpose of session I was to introduce and recognize personal values, and participants were given ACT metaphors and introduced several types of personal values. In session 2, the Value Assessment Rating form was administered for all the participants to complete. The goal in this session was for the participants to identify their values, acknowledge their reasoning, and discuss their experiences with other participants in the group. By identifying and understanding personal values, participants are expected to maintain a more positive attitude toward their personal experiences.

Session 3 is the start of the committed action core process, which consists of ACT metaphors and worksheets about values and personal goals. The purpose of this session was to associate participants' personal values with their respective personal goals, hence guiding the participants to actively construct attainable, specific, and measurable goals. The personal goals were particular about work and career aspects to create a healthier social environment in the nursing home. Session 4 consists of short-term goal setting for all the personal goals previously discussed in session 3 and building a commitment to complete their personal goals by making a promise with each other. All the participants came through an agreement to oversee and to help each other's personal goals completion.

\section{Instruments}

Psychological flexibility among nursing home staff was measured using the Acceptance and Action Questionnaire (AAQ-2R) by Bond et al. (20II) and translated to Indonesian by Mubina (20I4). AAQ$2 R$ has seven items representing negative views and emotions related to psychological flexibility, with 


\section{Journal of Educational, Health and Community Psychology Rahmalia, \\ Vol I0, No 3, 202I E-ISSN 2460-8467 Ratnasari.}

7-point Likert scales of the extent to which the statements conform to their current condition. The Likert scale ranges from the statement entirely not true (I) to always true (7) related to their current condition. All the answers are reversely coded due to all of them being negative statements, then summed to produce a total psychological flexibility scale. The reliability measured by their internal consistency resulted in a Cronbach alpha value of .683 (moderate reliability), and the validity test of the instrument was conducted with content validity by expert judgment after back translation. Work stress was measured using Work Stress Symptoms Scale by Widiastuti (20I5), developed based on the work stress theory from Beehr \& Newman (1978). The scale consists of 31-items divided into three dimensions: physical symptoms (I I-items), emotional symptoms (II-items), and behavioral symptoms (9-items). All items are using 5-point Likert scales on how much they agree, from completely not agree to very agree with the statements provided, thus the higher the score means they have a higher level of work stress. Reliability tests resulted in an alpha coefficient of .8I, with a validity test conducted through expert judgment related to the instrument's content validity.

Table 2

Psychological Flexibility Symptoms Sample Items

\begin{tabular}{ll}
\hline Item no. & Sample item \\
\hline 3 & I worry about not being able to control my worries and feelings. \\
6 & It seems like most people are handling their lives better than I am. \\
\hline
\end{tabular}

Table 3

Work Stress Symptoms Sample Items

\begin{tabular}{lll}
\hline Symptoms & Item no. & Sample item \\
\hline Physical & I & I have a headache while working \\
Emotional & 20 & I feel that my abilities are less than other colleagues \\
Behavioral & 28 & I feel like missing work is not a big deal \\
\hline
\end{tabular}

Work performance among nursing home staff was measured using the Indonesian translation of the InRole Performance Scale (Angguna, 2017). The scale was based on the In-Role Performance subscale developed by Williams \& Anderson (1991), translated by Angguna (2017) with good reliability (Cronbach alpha value .7< $<<.8$ ) and good validity (Pearson $r$ value $>.2$ ). Validity test was performed through item analysis by corrected-item total correlation method, with results showing that each item 


\section{Journal of Educational, Health and Community Psychology Rahmalia, \\ Vol I0, No 3, 202 I E-ISSN 2460-8467 Ratnasari.}

correlated with the overall instrument score in a coefficient range of .39 until .59 . The scale consists of 7-items with negative and positive items; staff responded on a 5-point Likert scale with I representing completely not agree and 5 representing very agree with the statement. All the negative items were reverse coded and summed with positive items to provide the total work performance score. For the quality of life, nursing home staff were measured using an Indonesian translation of the WHO Qualityof-Life (WHOQOL-BREF) (WHO, 2004). WHOQOL-BREF consists of 26-items within four domains: physical health, psychological, social relationships, and environment, with two additional items related to general health questions. Translation of WHOQOL-BREF Indonesian version was conducted on behalf of WHO, with previous study showing that WHOQOL-BREF has high test-retest reliability among the general Indonesian population (Purba et al., 2018).

Table 4

In-Role Performance Sample Items

\begin{tabular}{lll}
\hline Items & Item no. & Sample item \\
\hline Positive items & I & I fulfill the responsibilities or duties specified in my job description \\
Negative items & 5 & Sometimes I fail to do a task that is important to my job \\
\hline
\end{tabular}

Table 5

Quality of Life Symptoms Sample Items

\begin{tabular}{ll}
\hline Item no. & Sample item \\
\hline 5 & How much do you enjoy life? \\
10 & Do you have enough energy for everyday life? \\
\hline
\end{tabular}

Along with the instruments, open-ended questions were also administered after every session completed as qualitative data. The questions provided are, "before participating in this session, I feel..." and "After participating in this session, I feel...". At the end of the group therapy, qualitative data collection was also administered with questions about how much the participant agrees that the group therapy was enjoyable, beneficial, and motivated to change. After completing the whole therapy, additional qualitative data were also obtained with open-ended questions about the benefits of group therapy.

\section{Ethical Considerations}


The Head Director of the participating nursing home offered their approval for their institution to participate in the study. Approvals were also received from PSTW Budi Mulia 3 Jakarta as the managing institution of STW Centex, South Jakarta, Indonesia. A preliminary meeting with all the nursing home staff was also organized to address any queries about the group therapy, instruments, and personal data protection related to the study.

\section{Data Analysis}

All psychological flexibility, work stress, in-role performance, and quality of life questionnaires were completed and included in the analyses. Statistical analyses were performed using IBM SPSS 22 for Windows, with a $5 \%$ level of significance set for all tests. Descriptive statistics were summarized using mean and standard deviation values, and group therapy implementation effectiveness was analyzed by comparing means from pretest and posttest scores using the Wilcoxon Signed-Rank test. For the qualitative data, open-ended responses were coded to identify recurrent/emergent themes within the data by grouping excerpts with similar themes.

\section{Results}

Quantitative Results

Pretest and posttest individual scores, means, and standard deviations appear in Table 2. As summarized in Table 2, each participant displays a total score difference after participating in the group therapy. Each participant generally had an increased score in psychological flexibility, in-role performance, and quality of life scores, while work stress scores are generally decreased after the group therapy. 


\section{Journal of Educational, Health and Community Psychology Rahmalia, \\ Vol I0, No 3, 202 I E-ISSN 2460-8467 Ratnasari.}

Table 6

Pretest and Posttest Individual Result Scores

\begin{tabular}{lllllllll}
\hline Participant & \multicolumn{2}{l}{$\begin{array}{l}\text { Psychological } \\
\text { flexibility }\end{array}$} & \multicolumn{2}{l}{ Work stress } & In-role performance & Quality of life \\
\hline & Pretest & Posttest & Pretest & Posttest & Pretest & Posttest & Pretest & Posttest \\
\hline A & 37 & 38 & 65 & 49 & 24 & 32 & 90 & 93 \\
B & 27 & 31 & 84 & 74 & 23 & 24 & 76 & 84 \\
C & 35 & 42 & 53 & 37 & 29 & 32 & 81 & 103 \\
D & 22 & 30 & 97 & 101 & 24 & 25 & 85 & 92 \\
E & 35 & 37 & 65 & 58 & 26 & 28 & 90 & 90 \\
F & 39 & 46 & 88 & 77 & 23 & 26 & 77 & 86 \\
G & 28 & 33 & 80 & 83 & 21 & 27 & 74 & 91 \\
\hline Mean & 31.86 & 36.71 & 76 & 68.43 & 24.29 & 27.21 & 81.86 & 91.29 \\
SD & 6.23 & 5.88 & 15.47 & 21.8 & 2.563 & 3.2 & 6.62 & 6.1 \\
\hline
\end{tabular}

Table 3 represents pretest and posttest means comparison and Wilcoxon Signed-Rank test results. The difference between means is statistically significant for psychological flexibility, in-role performance, and quality of life $(p<.05)$, revealing an improvement in general psychological health. For the work stress, the difference is not statistically significant between pretest and posttest mean scores.

Table 7

Pretest and Posttest Mean Comparison

\begin{tabular}{llll}
\hline Variable & Mean difference & Z-score & Asymp. sig. (2-tailed) \\
\hline Psychological Flexibility & +4.85 & -2.371 & .018 \\
Work Stress & -7.57 & -1.863 & .063 \\
In-Role Performance & +3.42 & -2.375 & .018 \\
Quality of Life & +9.43 & -2.201 & .028 \\
\hline
\end{tabular}

Qualitative Results

After each session, all participants were administered open-ended questions related to their personal experience with the group therapy-particularly about feelings and experiences before and after sessions. Overall, results from open-ended questions were grouped into two answers: negative and positive experiences. All negative answers are experienced before sessions, and all positive answers are experienced after the session was completed. 


\section{Journal of Educational, Health and Community Psychology Rahmalia, \\ Vol I0, No 3, 202 I E-ISSN 2460-8467 Ratnasari.}

Table 8

Qualitative Themes: Nursing Home Staffs Reports in Personal Values Sessions

\begin{tabular}{ll}
\hline Core process: personal values (Session I \& 2) & After \\
\hline Before & Comprehension \\
\hline Comprehension & - Feeling like found one's purpose in life. \\
- Does not understand the concept. & - Learned each other's personal values. \\
- Confused about own personal values. & - Learned own strengths and weaknesses. \\
- Feeling like they do not know themselves. & - Feeling happy. \\
Emotion & - Feeling content. \\
- Feeling anxious. & Confidence \\
Confidence & - Higher self-confidence. \\
- Low self-confidence. & - Feeling better about oneself. \\
- Doubtful about one's ability to change. & Thoughtfulness \\
Thoughtfulness & More concerned with each other. \\
- Inconsiderate with the society. & Go not feel self-conscious about the underlying \\
- problem. & - Learned to appreciate life. \\
Gratitude & Adaptability \\
- Being ungrateful with life. & - Motivated to face future hardships. \\
- Does not appreciate one's personal values. & - Feeling more in control with life. \\
Adaptability & Feeling hard to adapt to the change.
\end{tabular}

In personal values sessions, improvement was reported related to several qualitative themes: comprehension about personal values and psychological health, emotions, self-confidence level related to their ability to change, thoughtfulness about the environment, gratitude with life, and the ability to adapt to life changes. Answers from open-ended questions showed that, in general, participants felt the group therapy improved their knowledge in mental health issues and psychology, particularly about their personal values and how values influence their emotions, their perspective on life, and their willingness to change. This improvement also results in more positive emotional experiences, higher self-confidence, and feeling more grateful towards life. In addition, personal values sessions also improved participants' thoughtfulness, specifically about their concern with the social environment in the nursing home and how the group therapy facilitates their attention to the psychological problem that occurred within their group. After participating in the sessions, participants display increased 


\section{Journal of Educational, Health and Community Psychology Rahmalia, \\ Vol I0, No 3, 202 I E-ISSN 2460-8467 Ratnasari.}

awareness of their surroundings, leading to their ability to adapt to job demands and future challenges in the nursing home.

Table 9

Qualitative Themes: Nursing Home Staffs Reports in Committed Action Sessions

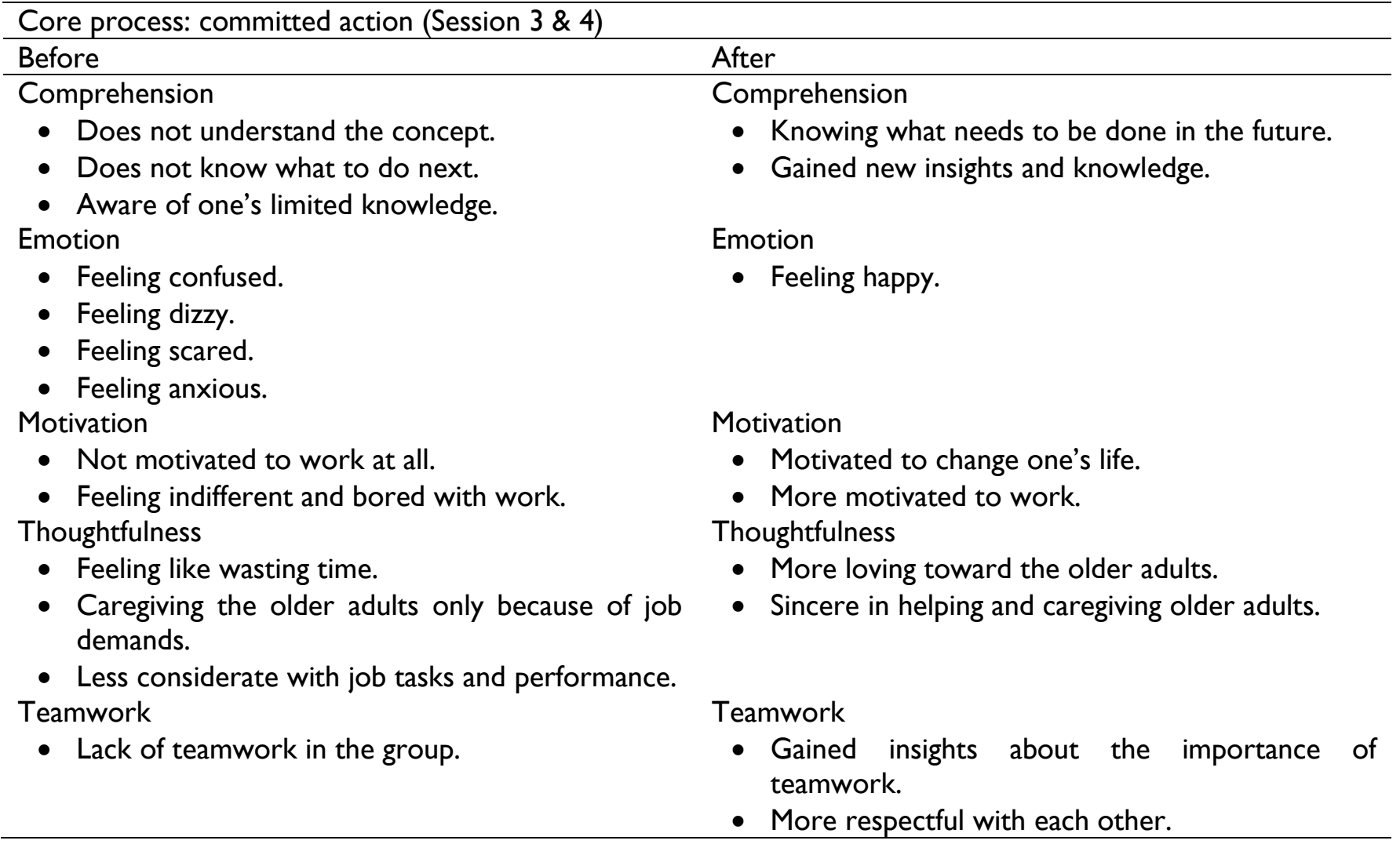

Participants also reported improvement after being involved in committed action sessions (session 3 \& 4), with qualitative themes related to comprehension, emotion, motivation, thoughtfulness, and teamwork within the group. Comprehension was a recurring theme associated with previous sessions, with reports of improved knowledge about action that needs to be done to initiate a change. Participants also reported a change in emotions toward a more positive feeling (i.e., feeling happier) after the group therapy. Committed action sessions also highlight the ability to formulate a more attainable goal, motivating staff to start taking actions related to their job demands within the nursing home. Consistent with previous sessions about personal values, committed action sessions also 
highlight changes related to thoughtfulness, which facilitates participants to be more caring and attentive with care recipients. This improvement was resulted from an action plan from nursing home staff to engage in more sincere caregiving with older adults, thus creating a more positive attitude towards work. Brief-ACT, conducted in a group format, encourages staff to participate in joint activities, both with fellow staff and care recipients in the nursing home. Improvement in teamwork was reported in open-ended questions after participants finished committed action sessions, as several participants planned to involve themselves in joint activities after the group therapy was completed.

Additional qualitative data results from open-ended questions were also obtained after participants completed the whole group therapy. All participants agreed that the group therapy was overall enjoyable, beneficial for them, and motivates them to initiate a change in their lives, mainly related to their lives in the nursing home as a staff. Several examples of therapy benefits reported in the openended questions are, "(The therapy) helped me to become more eager in finishing work tasks," "(I can) get to know myself better," and "(I can) understand the meaning of our group and helped us to become more united." In general, participants felt an increase in motivation to work, feeling more connected with each other, and learned new knowledge about themselves after participating in the brief-ACT group therapy.

\section{Discussion}

From all participants in the study, results displayed an increased level of psychological flexibility, in-role performance, and quality of life among nursing home staff, while the decreased level of work stress was also reported after the group therapy was completed. The results reveal statistically significant mean differences in psychological flexibility, in-role performance, and quality of life. However, the decreased level of work stress among nursing home staff was not significant through statistical analysis. In this study, the pretest-posttest instrument used in the study consistently documents improvement in all variables. In psychological flexibility, items from AAQ-2R such as, "My painful experiences and memories make it difficult for me to live a life that I would value" consistently answered as leading to 'not true' in posttest measures, compared to answers leading to 'often true' or 'almost always true' related to their 
current condition when pretest was conducted. Literature suggests ACT mainly aims to increase psychological flexibility (Hayes, Strosahl, \& Wilson, 20I2), which facilitates individuals to interpret stressors often faced at work in a more positive manner. The increase in psychological flexibility through ACT then improves general mental health (e.g., Losada et al., 20I5; Davis, Deane, \& Lyons, 20I5), which can also be described by other variables, such as performance in work and quality of life.

In qualitative results, nursing home staff reported feeling positive emotions, feeling grateful, more thoughtful with the society, and reports of increased teamwork. In contrast, lack of knowledge, low self-confidence, and feeling indifferent to the group was reported when participants asked about their feelings before being involved in every session. In general, these qualitative themes are related to increased social support in the group, as implementing group therapy helped participants exchange social support-a potential resource for increasing the effectiveness of therapy that individual ACT participants do not experience (George, 2016). Group therapy also facilitates qualitative feedback from other group participants, thus increasing personal satisfaction with the therapy conducted (George, 2016). Moreover, participants reported an increase in insights about each other, consequently building respect and a positive attitude within the group. Implementing therapy in a group format presents its challenges for participants as they must display their vulnerability to the group but will build a deeper emotional bond among participants if the group is being supportive and non-judgmental (Eddins, 2020). This emotional bond results in a more profound understanding among nursing home staff, regardless some moments would be triggering discomfort for most of the participants.

In the in-role performance scale and quality of life items, most participants also reported improvement in several items, such as, "I earnestly perform expected job tasks," and "How would you rate your quality of life?' from in-role performance and quality of life scales, respectively. These results are consistent with previous studies, particularly about personal values and committed action-based interventions, as previous studies found that both processes (i.e., values and committed action) are beneficial. Studies found that both processes effectively increase performance (Fellner \& Sulzer-Azaroff, 1985; Chase et al., 2013) and quality of life (Lundgren et al., 2008). Other studies also found increased well-being among employees who behave consistently according to their values in the workplace (Castro, 
Rehfeldt, \& Root, 2016), which creates a more positive attitude towards work. The committed action core process also forms a more positive and persistent attitude, particularly when employees face unpleasant experiences. Persistence in attitude is initiated as a committed action process tries to change complex, long-term goals into shorter and more attainable goals, motivating individuals to complete them (Trindade et al., 2015).

In work stress scales, participants also displayed improvement, particularly in emotional and behavioral symptom domains. However, the improvement in work stress was not statistically significant when tested with the Wilcoxon Signed-Rank test $(p>.05)$. One factor that might account for the current finding is the theoretical basis for the Work Stress Symptoms Scale, which focused on three domains: physical, emotional, and behavioral symptoms of work stress (Beehr \& Newman, 1978). Work stress, which is conceptualized into some of these symptoms, is also influenced by various factors such as age, preexisting health conditions, and occupation (Beehr \& Newman, 1978). Several items listed in the Work Stress Symptoms Scale include "I feel stiff in my muscles" from the physical domain and "I consume alcohol" from the behavioral domain are the indicators that describe the consequences of work stress symptoms in employees. However, these symptoms among nursing home staff might also be influenced by factors other than the persisting work stress. The post-intervention informal interview was conducted with the participants, and the results showed most of the nursing home staff already had preexisting health conditions and reported behavioral habits (e.g., long-term smoking)that might affect their answers in the work stress instrument.

Furthermore, several conditions need to be considered in interpreting the results of this study. The first condition is that the Wilcoxon Signed-Rank test results in this study are based on a low sample $(n=7)$. Second, in evaluating the therapy outcomes, this study relies on using self-report instruments where there is a risk of less objective reporting, particularly reports of stress symptoms (Beehr \& Newman, 1978). The author also did not take follow-up measurements to determine the resistance of the intervention effect in this group therapy, which is the essential element in the context of psychology studies (Hedeker \& Gibbons, 2016). Therefore, the results of this study do not have adequate data to determine the intervention effects over a more extended period or in broader 
caregiver populations. However, this study provides preliminary findings related to acceptance and commitment-based intervention in organizational settings and how the intervention affects psychological flexibility, work stress, in-role performance, and quality of life among staff, particularly those working in nursing homes. This study provided a new perspective for future research about ACT in group settings with emphasis on two core processes: personal values and committed action, considering the current literature has not been much directed at each core process in ACT, including the engaged response styles (i.e., values and committed action) (Trompetter et al., 20I3).

\section{Conclusion}

This study explored the effects of brief Acceptance and Commitment group therapy for nursing home staff, focusing on personal values and committed action core processes. Quantitative and qualitative results showed positive effects for all nursing home staff who participated in the study, with increased psychological flexibility, in-role performance, quality of life, and decreased work stress after the group therapy was completed. Participants also reported positive experiences when assessed with openended questions related to their experience with the therapy. For psychological flexibility, in-role performance, and quality of life, the effects were statistically significant, while the decreased level of work stress was not statistically significant. One explanation that might account for the finding was the uncontrolled preexisting condition that might affect the participant's answer in the instrument. Several limitations previously mentioned reduce the generalizability of this study, yet this study provides new findings related to ACT's feasibility for caregivers. Subsequently, a randomized controlled trial for nursing home staff should be a high priority for future research.

\section{Acknowledgment}

The author acknowledges all staff in Sasana Tresna Werdha Centex for their involvement and participation in this study. 


\section{Journal of Educational, Health and Community Psychology Rahmalia, \\ Vol I0, No 3, 202 I E-ISSN 2460-8467 Ratnasari.}

\section{References}

Angguna, E. H. (2017). Peran job insecurity sebagai mediator pada hubungan antara perceived organizational support dan in-role performance (Publication No. S67582) [Undergraduate Thesis, Universitas Indonesia]. OPAC Universitas Indonesia Library.

Babu, G. R. (2016). Association of quality of life and job stress in occupational workforce of India: findings from a cross-sectional study on software professionals. Indian Journal of Occupational and Environmental Medicine, 20(2), I09-II3. DOI: https://doi.org/I0.4I03/00 I9-5278.197544.

Banaszak-Holl, J., \& Hines, M. A. (1996). Factors associated with nursing home staff turnover. Gerontologist. Aug;36(4):5I2-7. DOI: I0.1093/geront/36.4.5I2. PMID: 877I 979.

Beehr, T. A., \& Newman, J. E. (1978). Job stress, employee health, and organizational effectiveness: a facet analysis, model, and literature review. Personnel Psychology, 3I, 665-699.

Bond, F. W. (20I I). Preliminary psychometric properties of the acceptance and action questionnaire-II: a revised measure of psychological inflexibility and experiential avoidance. Behav Ther. Dec, 42(4):676-88. DOI: 10.1016/j.beth.20I I.03.007. Epub 20I I May 25. PMID: 22035996.

Boumans, N. P. \& Dorant, E. (2014). Double-duty caregivers: Healthcare professionals juggling employment and informal caregiving. a survey on personal health and work experiences. J Adv Nurs. 70(7): I604-I5. DOI: 10.I I I I/jan. I2320. Epub 2013 Dec 2. PMID: 24289650.

BPS.(20I8). Statistik penduduk lanjut usia 2017. Jakarta: Badan Pusat Statistik.

Cagle, J. G. (2017). Caring for dying patients in the nursing home: Voices from frontline nursing home staff. Journal of Pain and Symptom Management, 53(2), 198-207. DOI: https://doi.org/10.1016/j.jpainsymman.2016.08.022.

Castle, N. G. Engberg, J. \& Men, A. (2007). Nursing home staff turnover: Impact on nursing home compare quality measures. Gerontologist. Oct;47(5):650-6I. DOI: 10.1093/geront/47.5.650. PMID: 17989407.

Castro, M., Rehfeldt, R. A., \& Root, W. B. (2016). On the role of values clarification and committed actions in enhancing the engagement of direct care workers with clients with severe developmental disorders. Journal of Contextual Behavioral Science. DOI: http://dx.doi.org//0.1016/j.jcbs.2016.09.003. 


\section{Journal of Educational, Health and Community Psychology Rahmalia, \\ Vol I0, No 3, 202 I E-ISSN 2460-8467 Ratnasari.}

Chase, J. A. (20I3). Values are not just goals: Online ACT-based values training adds to goal setting in improving undergraduate college student performance. Journal of Contextual Behavioral Science. 2 79-84. DOI: http://dx.doi.org/10.1016/j.jcbs.2013.08.002.

Chen, M. C. (2017). Effects of home-based long-term care services on caregiver health according to age. Health and Quality of Life Outcomes, I5(I), 208. DOI: https://doi.org/I0.II86/s I2955-0170786-6.

Cohen, A. \& Liu, Y. (20II). Relationships between in-role performance and individual values, commitment, and organizational citizenship behavior among Israeli teachers. International Journal of Psychology, 46 (4), 27I-287. DOI: 10.1080/00207594.2010.5396I3.

Cohen-Mansfield, J. (1995). Stress in nursing home staff: a Review and a theoretical model. Journal of Applied Gerontology, 14, 444-466.

Collins, A., O'Brien, W. \& Winterich, C. (2003). a Meta-analysis of stress management programs (unpublished manuscript).

Cresswell, J. D., Welch, W. T., Taylor, S. E., Sherman, D. K., Gruenewald, T. L., \& Mann, T. (2005). Affirmation of personal values buffers neuroendocrine and psychological stress response. Psychological Science, 16, 846-85I.

Crudup, B. M. (2016). The associations between values, committed action, and cardiovascular reactivity (Publication No. 830). [Doctoral Dissertation, University of Mississippi]. Electronic Theses and Dissertations. https://egrove.olemiss.edu/etd/830.

Davis, E., Deane, F., \& Lyons, G. (2015). Acceptance and valued living as critical appraisal and coping strengths for caregivers dealing with terminal illness and bereavement. Palliative and Supportive Care, I3(2), 359-368. DOI:10.10I7/SI47895I5I400043I.

Eddins, R. (2020). Acceptance \& commitment therapy in group practice. Retrieved from https://hgps.org/newsletter/acceptance-commitment-therapy-in-group-practice/.

Fellner, D. J. \& Sulzer-Azaroff, B. (1985). Occupational safety. Journal of Organizational Behavior Management, 7:I-2, 3-24, DOI: I0.I300/J075v07n0I_02.

Fowler, N. R. (202I). Feasibility and acceptability of an acceptance and commitment therapy intervention for caregivers of adults with Alzheimer's disease and related dementias. BMC Geriatrics. 2I: I27. https://doi.org/I0.I I86/s I 2877-02 I-02078-0. 


\section{Journal of Educational, Health and Community Psychology Rahmalia, \\ Vol I0, No 3, 202 I E-ISSN 2460-8467 Ratnasari.}

George, C. (2016). An exploration of caregiver burden and positive gain in dementia, and development of an acceptance and commitment therapy group intervention (URI: http://hdl.handle.net//842/23506) [Doctoral Dissertation, University of Edinburgh]. ERA University of Edinburgh.

Goergen, T. (200I). Stress, conflict, elder abuse and neglect in German nursing homes: A pilot study among professional caregivers. Journal of Elder Abuse and Neglects, I3, I-26.

González-Morales, M. G., \& Neves, P. (2015). When stressors make you work: Mechanisms Linking challenge stressors to performance. Work \& Stress, 29(3), 213-229. DOI: 10.1080/02678373.20I5.1074628.

Grunfeld, E. (2004). Family caregiver burden: Results of a longitudinal study of breast cancer patients and their principal caregivers. CMAJ: Canadian Medical Association Journal = Journal de l'Association Medicale Canadienne, I 70(I2), I795-80I. DOI: https://doi.org/I0.I503/cmaj.I03 I 205.

Hayes, S. C. \& Strosahl, K. D. (ed.) (2004). a Practical guide to acceptance and commitment therapy. New York: Springer.

Hayes, S., Strosahl, K., \& Wilson, K. (20I2). Acceptance and commitment therapy: The Process and Practice of Mindful Change. New York: Guilford Press.

Hedeker, D. R., \& Gibbons, R. D. (2006). Longitudinal data analysis. Hoboken, NJ: Wiley-Interscience.

Iglehart, A. P. (1990). Turnover in the social services: Turning over to the benefits. Social Service Review, 64, 649-657.

Jackson, S. E., Schwab, R. L, \& Schuler, R. S. (1986). Toward an understanding of the burnout phenomenon. Journal of Applied Psychology, 7I,630-640.

Jakarta Open Data. (2018). Data jumlah warga binaan panti sosial bulan Desember 2018. Retrieved from http://data.jakarta.go.id/dataset/data-jumlah-wbs-pantisosial/resource/02e092b4-e42 I -4b0 I-aa994elc000dale2.

Jolley, S. et al. (2020). Group acceptance and commitment therapy for patients and caregivers in psychosis services: Feasibility of training and a preliminary randomized controlled evaluation. British Journal of Clinical Psychology, 59(4) 524-55I. DOI:I 0. I I I I/bjc. 12265.

Losada, A. et al., (20I5). Cognitive-behavioral therapy (CBT) versus acceptance and commitment therapy $(A C T)$ for dementia family caregivers with significant depressive symptoms: Results of a randomized clinical trial. Journal of Consulting and Clinical Psychology, 83(4), 760-772. DOI: 10.1037/ccp0000028. 


\section{Journal of Educational, Health and Community Psychology Rahmalia, \\ Vol I0, No 3, 202 I E-ISSN 2460-8467 Ratnasari.}

Lu,Y-K et al. (2019). Reciprocal relationship between psychosocial work stress and quality of life: the role of gender and education from the longitudinal study of the survey of health, ageing and retirement in Europe. BMJ Open, 9, e02705I. DOI:I0.II36/bmjopen-20I8-02705I.

Lundgren, T., Dahl, J., Yardi, N., \& Melin, L. (2008). Acceptance and commitment therapy and yoga for drug-refractory epilepsy: a randomized controlled Trial. Epilepsy \& Behavior, 13(1), 102-108. DOI:10.1016/j.yebeh.2008.02.009.

Márquez-González, M., Losada, A., \& Romero-Moreno, R. (20l4). Acceptance and commitment therapy with dementia caregivers. In N. A. Pachana \& K. Laidlaw (Eds.), The Oxford Handbook of Clinical Geropsychology, (pp. 658-674). Oxford University Press.

Maslach, C. (1982). Burnout: The cost of caring. Englewood Cliffs, NJ:Prentice-Hall.

Moody, H. R. (1983). Ethical dilemmas in long-term care. In G. Getzel \& M. J. Mellor (Eds.), Gerontological Social Work Practice in Long-Term Care (97-I I I). New York: Haworth Press.

Mosher, C. E. et al., (2019). Acceptance and commitment therapy for symptom interference in advanced lung cancer and caregiver distress: a Pilot randomized trial. Journal of Pain and Symptom Management, 58(4), 632-644.

Mubina, N. (2014). Efektivitas acceptance commitment therapy dalam menurunkan experiential avoidance pada dewasa muda dengan pengalaman negatif terhadap figur ayah (Publication No. T42196) [Master's Thesis, Universitas Indonesia]. OPAC Universitas Indonesia Library.

Murphy, L. R. \& Sauter, S. L. (2003). The USA perspective: Current issues and trends in the management of work stress. Australian Psychologist, 38(2), I 5 I-I 57.

Mustafa, O.M. (2015). Health behaviors and personality in burnout: a Third dimension. Medical Education Online. 20: 28I87. DOI: I0.3402/meo.v20.28I87.

O'Brien, W. H. (2019). Group-based acceptance and commitment therapy for nurses and nurse aides working in long-term care residential settings. The Journal of Alternative and Complementary Medicine, 25(7) pp. 753-76I. DOI: 10.1089/acm.2019.0087.

Olzmann, A. E. (2017). Acceptance and commitment therapy components and their relationship with caregiver burden in primary caregivers of individuals with dementia (Publication No. xavier 1493678269237335). [Doctoral Dissertation, Xavier University]. OhioLINK. 


\section{Journal of Educational, Health and Community Psychology Rahmalia, \\ Vol I0, No 3, 202 I E-ISSN 2460-8467 Ratnasari.}

Parsons, S. K., Simmons, W. P., Penn, K., \& Furlough, M. (2003). Determinants of satisfaction and turnover among nursing assistants. the results of a statewide survey. J Gerontol Nurs, 29(3):5I-8. DOI: I0.3928/0098-9|34-2003030I-II. PMID: I 2683308.

Purba, F. D. et al. (2018). Quality of life of the Indonesian general population: Test-retest reliability and population norms of the EQ-5D-5L and WHOQOL-BREF. PLOS ONE 13(5):e0197098. DOI: https://doi.org/I0.137I/journal.pone.0197098.

Ruddle, A., Mason, O., \& Wykes, T. (20II). A review of hearing voices groups: Evidence and mechanisms of change. Clinical Psychology Review, 3 I, 757-766.

Schmelzer, F. (2017). Positive well-being of people with a chronic pain disorder: The role of psychological inflexibility and engaged living (Publication No. 72975). [Master's Thesis, University of Twente]. University of Twente Student Theses.

Schwetschenau, H. M. (2008). The effectiveness of an acceptance and commitment intervention for work stress (Publication No. bgsul225686342). [Doctoral Dissertation, Bowling Green State University]. OhioLINK.

Sonnentag, S., Volmer, J. \& Spychala, A. (2008). Job performance. Micro Approaches (Sage Handbook of Organizational Behavior). I427-447. Retrieved from https://www.unibamberg.de/fileadmin/uni/fakultaeten/PPP_lehrstuehle/organisationspsychologie/Publikationen_JV/ Sonnentag_Volmer_Spychala_Job_Performance_2008.pdf.

Trindade, I. A., Ferreira, C., Pinto-Gouveia, J., \& Nooren, L. (2015). Clarity of personal values and committed action: development of a shorter engaged living scale. Journal of Psychopathology and Behavioral Assessment, 38(2), 258-265.

Trompetter, H. R. (20I3). Measuring values and committed action with the engaged living scale (ELS): Psychometric evaluation in a nonclinical sample and a chronic pain sample. Psychological Assessment, 25(4), 1235-1246. DOI: 10.1037/a00338I3.

Tumanggor, R. D., Elfira, E. \& Aizar, E. (2020). Female caregiver devotion as a stress factor in caring for hospitalized elderly in Indonesia. International Journal of Nursing Education, I2(2), I06- I I I.

Walser, R. D., \& Pistorello, J. (2004). ACT in Group Format. In S. C. Hayes, \& K. D. Strosahl (Eds.), A Practical guide to acceptance and commitment therapy. US: Springer.

WHO. (2004). Introducing the WHOQOL instruments. Retrieved from depts.washington.edu/seaqol/docs/WHOQOL_Info.pdf. 
Widiastuti, B. (2015). Gejala stres kerja dan bahaya psikososial pada pekerja kontraktor proyek repairing tangki 3 IT5 di PT Pertamina (Persero) Refinery Unit IV Cilacap Tahun 2015 (Publication No. S58977) [Undergraduate Thesis, Universitas Indonesia]. OPAC Universitas Indonesia Library.

Willemse, B. M. (20II). Nursing home care for people with dementia and residents' quality of life, quality of care and staff well-being: design of the living arrangements for people with dementia (LAD)-Study. BMC Geriatrics, I I, I I-24. http://www.biomedcentral.com/I47/ -23 I8/I I/I I.

Williams, L. J. \& Anderson, S. E. (199I). Job satisfaction and organizational commitment as predictors of organizational citizenship and in-role behaviors. Journal of Management, I7(3),60I-6I7. DOI: $10.1177 / 014920639101700305$.

Williams, J., Vaughan, F., Huws, J., \& Hastings, R. (20/4). Brain injury spousal caregivers' experiences of an acceptance and commitment therapy (ACT) group. Social Care and Neurodisability, 5(I), 29-40. DOI: I0.I I08/SCN-02-20I3-0005.

Wilson, K. G., \& Murrell, A. R. (2004). Values work in acceptance and commitment therapy: Setting a course for behavioral treatment. In S. C. Hayes, V. M. Follette, \& M. Linehan (Eds.), Mindfulness \& Acceptance: Expanding the Cognitive-Behavioral Tradition (pp. 120-151). New York: Guilford Press. 